BIBLID [1699-3225 (2006) 10, 19-26]

\title{
¿UNA CONVERSACIÓN OBSCENA?
}

La boda del Alcmeónida Megacles con Agariste, hija de Clístenes de Sición, fue según Heródoto uno de los fundamentos más firmes del poder de aquella familia ateniense, a cuya historia dedica el de Halicarnaso varios capítulos de tono muy elogioso en el libro VI de su Historia (121-32). Deseaba el padre casar a su hija con el mejor marido posible $\mathrm{y}$, aprovechando la presencia de gentes de todas partes con ocasión de unos Juegos Olímpicos en los que él mismo obtuvo una victoria con el tronco de cuatro caballos, proclamó un certamen entre cuantos jóvenes nobles quisieran alcanzar esas bodas, que, a su vez, dado el poder de Clístenes, podían suponer un ventajoso negocio.

La relación de pretendientes de todo el mundo helénico, desde Italia a Eubea, que acudieron a Sición al conjuro de la proclama recuerda por su forma y estructura a los catálogos de la épica. Entre ellos se hallaban dos jóvenes de Atenas, el citado Megacles y un Filaida, el hijo de Tisandro, Hipoclides, que en palabras de Heródoto era el más guapo y el más rico de los atenienses.

El caso es que, bien fuera movido por objetivos económicos que, al parecer, ponía a su alcance el Alcmeónida, o bien por el deseo de emparentar con una familia, la de los Filaidas, que tenía vínculos de sangre con los Cipsélidas de Corinto, Clístenes acabó por limitar su decisión a los dos jóvenes atenienses, Megacles e Hipoclides.

* Completo con este trabajo un estudio en la obra de Aristófanes del uso de iٓ $\pi$ o 5 y sus compuestos como formante léxico de nombres comunes y propios a los que confiere el valor de metáfora sexual. Una parte ("De caballos y meneos. Palinodia por Hipocino”, en E. Calderón et al., eds., Koinòs Lógos. Homenaje al Profesor José García López, Murcia 2006, 565-80) ha abordado los ejemplos contenidos en las comedias; aquí comentaré, entre otros ejemplos, su presencia en los fragmentos del cómico. 
Finalmente, cuenta Heródoto (6.129), se decidió por Hipoclides, pero este, que además de guapo y rico era un excelente bailarín, con la cabeza apoyada sobre una mesa y las piernas en alto, ejecutó unas pantomimas que disgustaron sobremanera a Clístenes. El padre de la novia cambió de opinión y decidió entregarle su hija

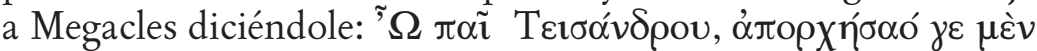

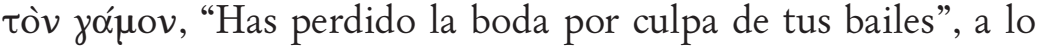


le importa".

Heródoto dice enseguida que la respuesta se convirtió en proverbio, y puede que tuviera amplio uso en la lengua hablada, ya que cuando aparece en la literatura escrita los autores no se sienten obligados a explicarlo; pero lo cierto es que, salvo su presencia en Los pueblerinos de su contemporáneo Hermipo (fr. 16 KasselAustin), de la que sabemos por una glosa de Hesiquio (o 1920):

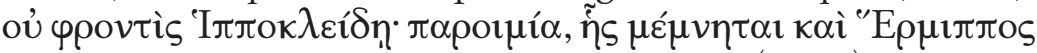
$\Delta \eta \mu o ́ \tau \alpha ı s$, que repiten casi exactamente Focio (o 363) y la Suda (o 978) ${ }^{2}$, no lo volvemos a encontrar hasta el siglo II de nuestra era por medio de Plutarco, quien en su crítica a Heródoto (Mor. 867 b 7) alude a la escena entre Clístenes e Hipoclides, cambiando el oú


de su cosecha, atribuyendo a Heródoto el mismo desprecio por la verdad que mostró Hipoclides ante la exclusión de que Clístenes le hacía objeto. Volvemos a encontrarlo en Ateneo (Epit. 2.2.133), Luciano (Apol. 15.22), Pseudo Luciano (Philopatr. 29. 18) y el emperador Juliano (9.2.12).

En cuanto a la narración de la anécdota, aparte del testimonio ya citado de Plutarco, la encontramos, siempre muy resumida, en paremiógrafos y lexicógrafos, como Pausanias (o 42), Diogeniano (7.21), Frínico (Ecl. 164.342) y Zenobio (5.31), que es el que da más detalles, explicando cómo fueron aquellos pasos de baile que privaron a Hipoclides de la boda que tenía ya prácticamente en la

${ }^{1}$ Para cuestiones de detalle de este relato remito a las notas de la traducción de C. Schrader, Heródoto. Historias, Madrid 1977-1989, I-V, y a las ediciones comentadas de G. Nenci, Erodoto. Storie, vol. VI, Milano 1998 y E.I. McQueen, A Commentary on Book 6 of Herodotus, London 2000.

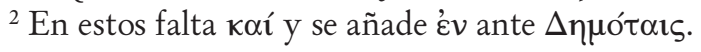




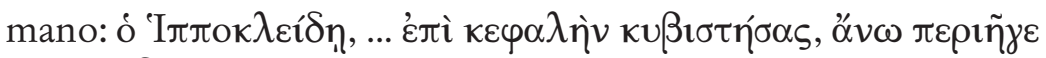

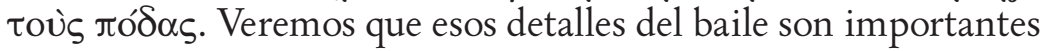
para la interpretación del pasaje que propondré.

Son también los autores de esos géneros quienes explican el sentido del proverbio. Según la glosa ya mencionada de Hesiquio, significa, por una parte, "No enfadarse, no tomarse las

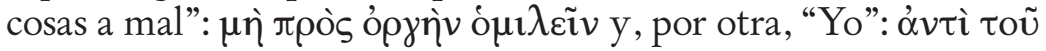
¿́uoí; de modo muy similar a la primera de las explicaciones de Hesiquio, los escolios a Luciano (65.15.4) señalan que se trata de una respuesta desenfadada y despectiva a alguien que se muestra excesivamente serio o solemne, cual sería el caso de Hipoclides y Clístenes. "Me importa un bledo" habría sido, según esas explicaciones, la respuesta de Hipoclides, y quizá en eso quedó la cosa, en la indiferencia o en el despecho y la frustración disfrazados de indiferencia del pretendiente.

La escena previa debió de estar cargada de erotismo. Sin duda Hipoclides, cabeza abajo y con las piernas en alto, mostró algo más que sus dotes de bailarín, y ello molestó a Clístenes ${ }^{3}$. En la línea de la interpretación que propondremos para el sentido del nombre de Hipoclides en esta escena es muy verosímil la idea de

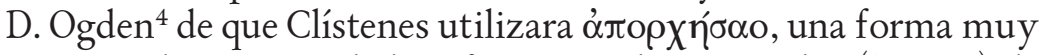
poco usada, como velada referencia a los testículos (ő $\chi^{\varepsilon \varepsilon ı)}$ de Hipoclides; Clístenes le habría dicho veladamente al joven: "Tus pelotas te han dejado sin boda". Por otra parte, como veremos enseguida, un nombre como Hipoclides puede tener connotaciones eróticas, y ello abre, a mi entender, la posibilidad de que también la respuesta aparentemente correcta aunque un tanto desabrida del así llamado escondiera una obscenidad, un campo muy cultivado (y con gran elegancia y finura ${ }^{5}$ ) en la Historia de Heródoto. La conversación entre Clístenes y el pretendiente, que en su

${ }^{3} \mathrm{La}$ indumentaria de los griegos no incluía ropa interior. Varios pasajes de las comedias de Aristófanes lo atestiguan de forma indirecta pero inequívoca, por ejemplo, Lys. 800, 824; Nu. 973-6. Cf. H. Licht, Vida sexual en la antigua Grecia (trad. esp.), Madrid 1976.

${ }^{4}$ The Crooked Kings of Greece, London 1997, 117 (apud McQueen, Commentary).

${ }^{5}$ Véanse las jugosas páginas que dedica al asunto J.S. Lasso de la Vega, con la amplísima bibliografía que siempre incluyó en sus trabajos, en su $D e$ Safo a Platón, Barcelona 1976, 204-7. 
apariencia superficial resulta simplemente fría y tensa, habría sido completamente obscena.

Sin embargo, hasta donde he podido comprobar, nadie ha propuesto hasta ahora que Hipoclides usara su nombre en sentido obsceno en este pasaje, lo cual resulta, en mi opinión, sorprendente. Lexicógrafos y paremiógrafos, cuyas obras pueden considerarse como un único testimonio en bloque ${ }^{6}$, no recogen esa posibilidad; Hesiquio, como veremos enseguida, conoce el valor erótico del nombre Hipoclides, pero lo menciona en una glosa ( 1835 ) distinta de la que hemos comentado. En cuanto a los comentarios modernos de Heródoto, Schrader coincide con la explicación de Ateneo recién citada y señala que Clístenes se disgustó porque, siendo la danza una actividad profesional, propia de esclavos, que su futuro yerno fuera experto en ella podía ir en desdoro de su nobleza; Nenci no comenta nada al respecto y tampoco lo hace McQueen. Por su parte, García Romero incluye el testimonio de Zenobio y comenta algunas variantes del mismo y de la explicación del proverbio, pero tampoco alude a que pudiera tener contenido obsceno ${ }^{7}$.

Pese a todo, pienso que igual que a un castellanohablante oír un nombre como Simeón puede sugerirle connotaciones escatológicas, a un griego de la Antigüedad la mención de un nombre compuesto mediante hipo-, "caballo (o yegua)”, podría evocárselas de índole erótica, ya que ese lexema se emplea en ciertos contextos como expresión metafórica de los genitales humanos de ambos sexos 8 . Así pues, creo que debe plantearse la posibilidad de que Hipoclides

${ }^{6}$ Es muy frecuente entre los autores de esos géneros que una misma explicación aparezca en todos ellos y con muy escasas diferencias de matiz, como hemos visto en la noticia de Hesiquio (o 1920) repetida en Focio y la Suda que hemos citado.

${ }^{7}$ F. García Romero - R. Mariño, Proverbios griegos. Menandro, sentencias, Madrid 1999, 190 y n. 334

${ }^{8}$ El doble sentido, si puede haberlo, siempre está al acecho y puede saltar en cualquier momento. En griego, un nombre tan común como Filipo puede

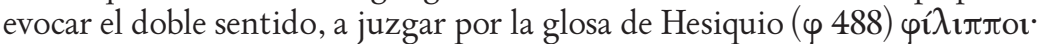
rotxoú, "hipófilos (es decir, coñófilos): adúlteros". Seguramente no costaría mucho imaginarse a algún Filipo (por ejemplo, el padre de Alejandro), a quien le cuadrara esa glosa. 
respondiera con una cruda, aunque disimulada, obscenidad a la decisión de Clístenes (sobre todo si también este había ocultado una obscenidad en sus palabras): según que entendamos la referencia de hipo- a la vulva o al pene, el joven se habría llamado a sí mismo "Coñoilustre" o "Pollailustre". Veamos ambas posibilidades y sus consecuencias.

Hipoclides significa “coño”, según Hesiquio ( 1835$)$ :

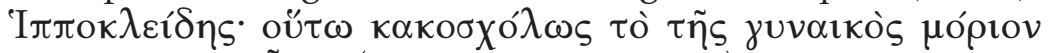

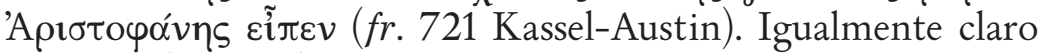

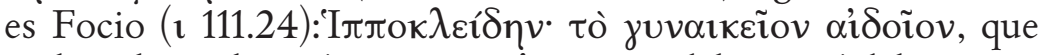
incluye la explicación: $\pi \alpha \rho \grave{~} \tau o ̀$ i $\pi \pi \varepsilon u ́ \varepsilon ı v$ del porqué del uso. En esta explicación, que alude a la realización del coito con la mujer cabalgando a horcajadas sobre el miembro del varón, se apoya Henderson ${ }^{9}$ para incluir, junto a los nombres Formisio (citado en Ec. 95) y Basilidas y Lacaras que menciona Hesiquio ( $\alpha$ 7248), el de Hipoclides como nombres propios usados en el sentido de "coño" en Aristófanes.

Que ï $\pi$ ros, "caballo (o yegua)", tiene ese mismo significado lo testimonian Hesiquio ( 1845 ), según el cual la palabra designa las partes de la mujer y las del hombre, el mismo Hesiquio (en la glosa $\varphi 488$ recogida en n. 8), el léxico Suda $(\delta 1164)$, que refiere que Diomedes obligaba a sus huéspedes a acostarse con sus feísimas

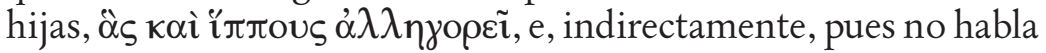
de ï $\pi$ đos sino de $\kappa \varepsilon ́ \lambda \eta \varsigma$, el caballo de silla o el banco de remero, Eustacio (Od. 1.222.12-4), al mencionar esa palabra entre los muchos nombres del coño. A todos ellos cabría aún quizá añadir dos pasajes de las cartas de Alcifrón (3.14. 1 y 4.11.8), donde se llama i $\pi \pi$ ó $\pi$ o $v$ os a dos rameras que esquilmaban a sus amantes, aunque cabe también la posibilidad de que semejante apelativo

${ }^{9} \mathrm{~J}$. Henderson, The maculate muse. Obscene language in Attic comedy, New York-Oxford 19912, 147-8. 
busque tan sólo añadir un plus de zafiedad y grosería al sujeto a quien se le aplica ${ }^{10}$.

Que Hipoclides signifique "pene" no lo dice, en cambio, ninguna fuente antigua; pero de que i $\pi \pi$ os sirva para nombrarlo hay muchos testimonios. Como se ha dicho, Hesiquio ( 1845 ) expresa esa identificación, apreciable también en los escolios a Ar. Ran. 429 y a Ar. Lys. 193 y en el comentario de Eustacio a la

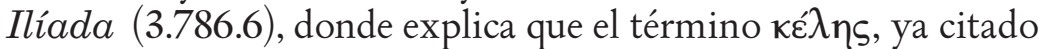
como "banco de remero" y "caballo de silla", designa al caballo o al banco sobre el que se sienta el jinete o remero.

Esta última referencia, sumada a alguna de las mencionadas

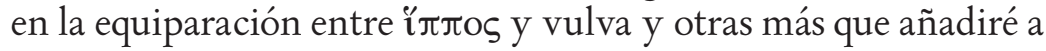
continuación apuntan a la cabalgada como metáfora del coito:

- En Focio (111.24) y en el escolio a Ar. Lys. 193, ya citados,

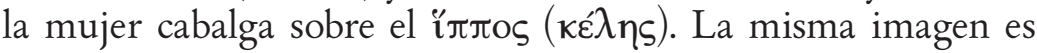
apreciable en las palabras del Corifeo de los Viejos en Lys. 6789 , con su alusión a las Amazonas y sus combates ' $\varepsilon \varphi$ ' ï $\pi \pi \omega v$ con


equivale a "pene, miembro viril".

- En otros ejemplos quien cabalga es el hombre, y lo hace sobre un caballo, í $\pi$ os, que en esos casos es elemento pasivo y equivale a "vulva". De esa situación hay testimonios directos e indirectos. Entre los primeros, el ya citado de Eustacio (Od.1.222.12), en el que se relacionan algunos nombres de la vulva, el pasaje de Ar. (Pax 899-904), que menciona una competición ecuestre con los hombres como jinetes, y un lema del Léxico de Zonaras ( $\alpha$ 196) que dice que la expresión "montando a caballo" no es muy elegante y que la emplea Aristófanes ${ }^{11}$ en boca de un hombre que dice querer montarse a una mujer. Entre los testimonios indirectos,

${ }^{10}$ En su uso metafórico, ĩ $\pi$ ros, además de "vulva” o "pene" es sinónimo de "grande", como podemos comprobar, entre otros lugares, en Hesiquio

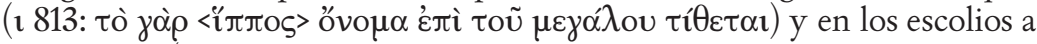

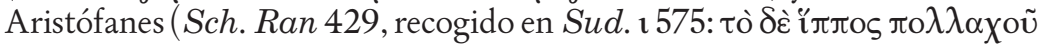

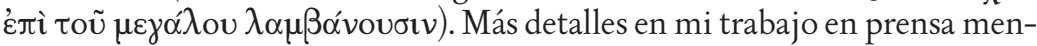
cionado en la nota inicial.

${ }^{11}$ En las Segundas Tesmoforias, una comedia perdida. 
el pasaje de Lisístrata (vv. 772-3) en que una mujer interpreta la predicción de un oráculo, según el cual Zeus pondrá encima lo que estaba debajo, en el sentido de que las mujeres se pondrán encima en el coito.

Asentado, pues, que ï $\pi \pi$ os puede significar tanto "vulva" como "pene", se plantea ahora la duda de cuál de las referencias se hallaría en el nombre de Hipoclides, si él quiso utilizarlo para dar con disimulo una respuesta obscena a Clístenes:

Podría aludir a la vulva, y la respuesta, escondida tras su literal "A Hipoclides no le importa", habría sido "No le importa a Coñoilustre". Si así fuera, habría utilizado su nombre para referirse a Agariste, que no sufriría por quedarse sin ese novio. La posibilidad es algo complicada y se opone a la explicación de Hesiquio (o 1920), según la cual, "[dice Hipoclides] en lugar de [decir] yo". Sin embargo, esta objeción podría quedar neutralizada por el hecho de que, como se ha dicho, Hesiquio no se hace eco de ninguna posible obscenidad al explicar el refrán en el que se incluye el nombre de Hipoclides. Además podría aportarse un uso semejante en Ar. Ran. 429, ya citado, donde el nombre de Hiponico, padre de Calias, se deforma en Hipobino (o Hipocino), "Caballofollador, Pichabrava", en alusión a Calias.

Podría aludir al pene, y la respuesta, igualmente disimulada bajo el inocuo "A Hipoclides no le importa", ser "No le importa a Pollailustre”. Esta respuesta, con la que el joven se aludiría directamente a sí mismo, eliminaría las objeciones que suscita la otra: el novio, frustrado y despechado, daría muestra de su autoestima, utilizando su nombre como referencia muy elogiosa a sus atributos viriles, y sugeriría a quien le había privado de la boda que pretendía que, provisto de tales prendas, no compartir el tálamo con Agariste no le preocupaba en exceso, pues no tendría dificultades para encontrar otra con la que hacerlo. Semejante posibilidad encuentra firme apoyo, a mi entender, en el relato de la escena según Heródoto y Zenobio, que hemos resumido al comienzo: Hipoclides habría mostrado en sus contorsiones algo a lo que aludió enseguida en su respuesta a la noticia de Clístenes de que se había quedado sin boda.

Creo que esta segunda posibilidad es preferible y que, si fuese admisible que la respuesta del muchacho fue disimuladamente obscena, sería oportuno traducir el ypovtís que contiene de forma 
que esa obscenidad se reflejara plenamente: "A Hipoclides no le importa" significaría "A Hipoclides se la suda"(o sea, "Me la suda"), y que si Ogden lleva razón al proponer un sentido veladamente obsceno en las palabras de Clístenes, toda la conversación entre Clístenes e Hipoclides:

(Clís.) "Has perdido la boda por culpa de tus bailes" (Hip.) "A Hipoclides no le importa"

habría ocultado realmente esta otra:

(Clís.) "Tus pelotas te han dejado sin boda" (Hip.) "Me la suda".

Luis M. Macía Aparicio

Universidad Autónoma de Madrid luism.macia@uam.es 